\title{
An Analysis of the Nuances and Practical Applications of Situational Leadership in the Management and Administration Of International Health Care Organizations
}

\author{
Blanca Alicia Luna \\ School of Business and Technology \\ Capella University, Minneapolis, Minnesota \\ E-mail: blancheut@sbcglobal.net \\ James Jolly \\ University of Phoenix \\ E-mail: jayee3@hotmail.com
}

\begin{abstract}
Over the past 10-20 years, the healthcare industry has experienced a volatile existence. This volatility is a direct result of competition, the growth of for-profit hospitals, the evolution of managed care, consumer demand for quality measures, the high cost of new medical technology, and increases in aging patient populations. These shifting environmental factors have forced international health care organizations and healthcare managers to develop new strategies to respond. The challenge that makes development of these skills so complex is that most health care practitioners received academic training in curriculum areas that are more focused on the clinical and operational aspects of healthcare and not heavily focused on the advanced study of organizational and situational leadership. The most common leadership development programs of choice are often Master of Nursing, Master of Public Health, Master of Counseling, Master of Social Work, the Doctor of Medicine, and Master of Health Administration. Although most healthcare related graduate programs often provide outstanding clinical skills development and a good framework advanced analysis, frequently the absence of academic courses that can effectively teach clinical professionals the aspects of adaptive and situational leadership are not offered.
\end{abstract}

Keywords: International healthcare, Situational leadership in healthcare, Situational leadership in management

\section{Introduction}

In the 2002 book, Primal Leadership, authors Daniel Goleman, Richard Boyatzis, and Annie McKee analyzed six different leadership styles as follows:

\subsection{The commanding leader}

Style: Gives clear directions and expects compliance.

Best used: In times of crisis, to kick-start a turnaround, and in dealing with "problem employees" who do not respond to other methods.

Most likely to say: "Do as I tell you!"

\subsection{The pace-setting leader}

Style: Sets goals and expects them to be achieved.

Best used: For getting results from a motivated and competent team.

Most likely to say: "Go for it!"

\subsection{The visionary leader}

Style: Moves people towards a shared vision.

Best used: When a new strategic direction is needed.

Most likely to say: "Come with me."

\subsection{The coaching leader}

Style: Develops people for the future. 
Best used: To help employees improve performance and develop long-term strengths.

Most likely to say: "Try this."

\subsection{The affiliative leader}

Style: Creates harmony and builds emotional bonds based on loyalty and trust.

Best used: To heal rifts in a team or to motivate people during stressful periods.

Most likely to say: "People come first."

\subsection{The democratic leader}

Style: Forges consensus through participation.

Best used: To build 'buy-in' and encourage input.

Most likely to say: "What do you think?"

The authors outline that the best leaders maintain a style repertoire, switching easily between "visionary," "coaching," "affiliative," and "democratic," and making rare use of less effective "pace-setting" and "commanding" styles. The authors' analysis of these methods is informed by research on the workplace climates engendered by the leadership styles of more than 3,870 executives.

Over the past 10-20 years, the healthcare industry has experienced a volatile existence. This volatility is a direct result of competition, the growth of for-profit hospitals, the evolution of managed care, consumer demand for quality measures, the high cost of new medical technology, and increases in aging patient populations. These shifting environmental factors have forced international health care organizations and healthcare managers to develop new strategies to respond. The challenge that makes development of these skills so complex is that most healthcare practitioners received academic training in curriculum areas that are more focused on the clinical and operational aspects of healthcare and not heavily focused on the advanced study of organizational and situational leadership. The most common leadership development programs of choice are often; Master of Nursing, Master of Public Health, Master of Counseling, Master of Social Work, the Doctor of Medicine, and Master of Health Administration. Although, any graduate program often provides outstanding clinical skills development and a good framework advanced analysis, often an absence of academic courses that can effectively teach clinical professionals the aspects of adaptive and situational leadership are not integrated.

\section{Nuances of Administration}

The hospital and healthcare administrator plays a vital a role in saving lives, without having to take scalpel in hand. Hospital administrators and executive manage hospitals, outpatient clinics, hospices, and drug-abuse treatment centers. Administrators make sure hospitals operate efficiently and provide adequate medical care to patients. Their responsibilities are numerous, constantly changing, and sometimes require the assistance of the medical and support staff. They act as liaisons between governing boards, medical staff, and department heads and integrate the activities of all departments so they function as a whole. Following policies set by a governing board of trustees, administrators plan, organize, direct, control and coordinate medical and health services. Administrators recruit, hire, and sometimes train doctors, nurses, interns, and assistant administrators. Administrators plan budgets and set rates for health services. In research hospitals, administrators develop and expand programs and services for scientific research and preventive medicine.

In teaching hospitals, administrators and managers aid in the education of new doctors. Administrators plan departmental activities, evaluate doctors and other hospital employees, create and maintain policies, help develop procedures for medical treatments, quality assurance, patient services, and public relations activities such as active participation in fund-raising and community health planning. Administrators also attend staff meetings, participate in health planning councils, go to fund-raising events, and travel to professional association conventions. A hospital administrator's job is difficult and demanding. They need to keep up with advances in medicine, computerized diagnostic and treatment equipment, data processing technology, government regulations, health insurance changes, and financing options. While doctors strive to keep patients healthy and alive, the hospital manager is doing his job in keeping the hospital alive and healthy.

Due to the turbulent and changing nature of the healthcare industry, administrators need to be more flexible, innovative, and adaptive in the ways that they lead. Past leadership processes have included large bureaucracies and inflexible structures. Although mechanistic structures can be effective in predictable and stable environments, they are not effective in rapidly changing environment. 


\section{Practical Applications of Situational Leadership}

To respond to challenges of leadership, professionals in the realms of health care will have to develop an effective understanding of a genesis of the situational or adaptive leadership model that was developed by Hershey and Blanchard, but one that responds to the changing aspects of organizational culture. Basically this means that based on the situation, leaders will have to use a variety of leadership styles to be effective. Leading today is about administrators and managers developing a firm understanding of the relationship between the leadership style, the organizational structure, and the organizational culture.

Organizational structure here means a framework that defines the boundaries of the formal organization and within which the organization operates, this definition is in consonance with Hatch and Cunliffe (2006) as "the relationships among the other parts of an organized whole (p. 101)." An effective organizational structure must ensure efficiency, precision, speed, continuity, discretion, and produce clear and light at the end of the tunnel.

It is known that every individual has something that psychologists have termed "personality." An individual's personality is made up of a set of relatively permanent and stable traits. When a person describes someone as innovative, angry, conservative, or wild, they are describing personality traits. An organization has a personality that is called the organization's culture.

The Hawthorne Studies research provided support and insight to the importance of organizational culture. His research outlined how work groups develop social networks that influence group behavior. These social networks are the building blocks of an organization's culture. Through and understanding of these social networks, leaders would be less likely to be frustrated and confused when challenging behavior and activities on the part of employees exist. Understanding the social structure of employee groups is necessary to decipher that an organizational culture is the result of a complex group learning process that is only partially influenced by the individual behaviors of one leader (Sonnenfeld, 1985). Organizational culture is a product of the experiences, expectations, values, and the approval of the organizational community. The culture develops and changes only when employees join together with their actions and activities to move the meter in the right direction (Schein, 1992).

Organizational culture refers to a system of shared meaning within an organization that determines, in large degree, how employees behave or act. In every organization, systems or patterns of values, symbols, rituals, myths, and practices that have evolved over time are present. These shared values determine, in large degree, how employees perceive their organizational environment and community. When confronted with a problem, the organizational culture restricts or dictates what employees do by suggesting the organization's "correct way" or "the way that we do things here" to conceptualize, define, analyze, and solve the problem.

Situational leadership is based on the premise that there is no single best way to lead. Leadership style needs to be adjusted based on the members of the group and based on the situation. Another factor involved in situational leadership is the maturity of the group. Hershey and Blanchard asserted the leader must assess the maturity of followers and adjust leading to the level demonstrated (Hersey \& Blanchard, 1977). The optimal leadership style of supervision, which is defined in terms of the combination of task-oriented behavior and relationship-oriented behavior, changes over time as the maturity level of the follower increases (Hersey \& Blanchard, 1977).

Low-maturity followers have low motivation and possibly low initiative, therefore, they require more direction; Low to moderately mature followers need direction plus personal attention; Moderate to highly mature followers require greater attention and a share in decision-making; Highly mature followers require freedom. Hersey and Blanchard also referred to this premise as the Life Cycle Theory (Hersey \& Blanchard, 1977).

In effect, Hersey and Blanchard are offering a very sensible premise: as the leader's subordinates become more mature, effective, and efficient, the leader should decrease the emphasis on structuring tasks and increase their emphasis on consideration of the whole picture.

\section{Historical Aspects of Situational Leadership}

The literature suggests that the application of situation leadership are dependent upon the task, the characteristics of the group, interpersonal relationships within the group and the characteristics of the organizational culture. The leader must outperform other members in the group through the examples that they and through their abilities to coach and develop others. Hoy and Miskel attempted to find the specific attributes of situation that would result in leadership emerging (Hoy\& Miskel, 1987). Hencley explained that "the situation approach maintains that leadership is determined not so much by the characters of the individuals as by the requirements of social situation" (Hencley, 1973, p. 38).

Hersey and Blanchard explained there were levels of support: 
(1) Directing Leaders define the roles and tasks of the 'follower', and supervise them closely. Decisions are made by the leader and announced, so communication is largely one-way (Hersey \& Blanchard, 1977).

(2) Coaching Leaders still define roles and tasks, but they seek ideas and suggestions from the follower. Decisions remain the leader's prerogative, but communication is much more two-way (Hersey and Blanchard, 1977).

(3) Supporting Leaders pass day-to-day decisions, such as task allocation and processes, to the follower. The leader facilitates and takes part in decisions, but control is with the follower (Hersey and Blanchard, 1977).

(4) Delegating Leaders are still involved in decisions and problem-solving, but control is with the follower. The follower decides when and how the leader will be involved (Hersey and Blanchard, 1977).

Effective leaders can adopt any of these four styles based on the situation and the persons being supervised (Hersey and Blanchard, 1977).

Many have written about the complex and contradictory advice given about being effective leaders (Sleeth and Johnston, 1996). Managers have taken on any number of new roles over the past decade leaving them rightfully confused in terms of what leadership or management style to adopt. Sleeth and Johnston argue that the Leadership Linking Model "incorporates several well-known leadership models, such as that promoted by Hersey and Blanchard, and facilitates the integration of their prescriptions" (1996, p. 16). These authors reinforce the situational leadership model when they say that leaders must adapt their styles based on the physical and psychological elements of the workplace and the task at hand (Sleeth and Johnston, 1996). The linking model comes into play in the diagnosis and planning of the needs of the work environment and the employees (Sleeth and Johnston, 1996).

Leebov and Scott (1991) asserted that managers in healthcare organizations are taking on new roles and must, therefore, change their styles of supervision and leadership. Two of those changes involve a focus on customer service and empowering employees.

Morrison (1996) also noted the velocity of change that is occurring today. Morrison calls it the second curve for executives and states that it is fueled by forces that cannot be controlled, such as new consumers, new markets, and new technology. The environment demands an executive, who is a visionary and who learns how to anticipate the next round of changes then, adapts the organization to meet them (Morrison, 1996).

Speaking directly to health care, McDonagh (1997) noted the changes in the field: the move to managed care, the increasing complexity of the system, multidisciplinary models of governance, the need for more collaboration, the influence of human rights, a patient-orientation, and the impact of technology, among others (McDonagh, 1997).

Leaders in today's healthcare organization need a different set of skills than in the past and, in fact, those who rely on older models of management will be far less successful than those who either incorporate what still works from previous styles with new styles or those who adopt the new ways to supervise, set expectations, develop accountabilities, shape behavior, and reinforce organizational strategy.

Situational leadership makes sense for health care institutions because, as Jobes and Steinbinder (1996) noted, these are turbulent times in the industry. This turbulence and lack of stability means dramatic changes in the roles of nurse executives and leadership styles that were successful in the past do not meet the demands of today's environment (Jobes \& Steinbinder, 1996). With the industry experiencing rapid and dramatic changes, one leadership style that has the potential for success is situation leadership.

Hernandez, Spivack and Zwingman-Bagley cited William Bridges, who said: "Change is situational: the new site, the new boss, the new team roles, and the new policy. Transition is the psychological process people go through to come to terms with the new situation" (Hernandez, Spivack \& Zwingman-Bagley, 1997, p. 38). Different situations, different employees require different leadership styles, those that consider the changes that are happening and that adjust for those changes.

The early research addressing situation leadership has been conflicting with more mixed results than those pointing either to its proven benefit or showing that it does not improve the environment. For instance, in 1991, Johnson and D'Argenio trained nurse administrators and executives in the Hersey and Blanchard Situational Leadership model (Krejci \& Wessel, 1997). These investigators did not find any significant changes in how nurse administrators perceived their own leadership style twelve months after the training (Krejci \& Wessel, 1997).

Norris and Vecchio (1992) conducted a study to determine the efficacy of situational leadership in health care; it was one of the first studies to be conducted in this venue. Situational leadership is perceived as having relevance to healthcare environments because there is are very clear norms in terms of supervisor-subordinate behaviors as well as a clear hierarchy of authority (Norris \& Vecchio, 1992). 
Situational leadership has garnered only mixed support through research studies (Norris and Vecchio, 1992). Norris and Vecchio's study contributed to the mixed results (1992). One of the major problems has always been how to determine which level of maturity subordinates fall into (Norris and Vecchio, 1992). The investigators, however, suggested that situational leadership may offer immeasurable benefits but those benefits will not be clearly outlined in literature until a variety of research issues can be overcome (Norris \& Vecchio, 1992).

The reality is that organizational culture is a set of shared values, beliefs, attitudes, norms, that shape the behavior and expectations of each member of the organization. The use of situational leadership with monthly, quarterly, semi-annual, and annual performance report cards for employees, managers, and the organization allows leaders to establish important understandings and accountabilities that influence and change organizational culture.

For instance, Tushman and O'Reilley (1997) stated: "Great managers are architects, network builders, and jugglers. They understand how to employ these roles to foster a culture that celebrates stability and change in order to endure success tomorrow." Simple common sense tells us that if managers are builders and architects then this seems realistic that they must adapt and juggle as problems arise and change occurs.

The application of situational leadership understands that distinct differences in being a manager and being a leader exist. Management develops the capacity to achieve set plans by planning, organizing, directing and controlling -creating organizational structure that helps to achieve these set goals. By contrast, leadership has to do with setting direction, aligning people, and achieving vision by inspiring and motivation employees (Kotter, 2001, p103). The major aspect of the an effective situational leader is to facilitate and foster collaboration, pooling employee knowledge, defining who needs to participate in strategy discussions, and asking critical questions. Successful situational leadership is about providing focus and learning in a manner that listens to employees at the bottom as well as employees at the top of the organization (Bennis, 1992).

\section{Situational Leadership Emerging Models}

According to the proponents of situational leadership, universal traits and behaviors do not exist, rather the success of the effectiveness of a leader is demonstrated on how well their behaviors adapt to different situations (Bateman \& Snell, 2004). Situational leadership allows individuals to become responsive to the potential benefits of the participatory approach to decision making and simultaneously knowing that in certain situations, they will have to make decisions on their own. The first situational model was proposed by Tannenbaum and Schmidt in 1958, this model and its arguments continue to be valid today. The premise of this model describes how managers should first consider the following three factors before leading: forces in the manager, which means the manager must incorporate personal values, preferences, feelings of security and confidence in subordinates. Forces in the subordinates signifies the employee's knowledge and experience, willingness to take on responsibility for decision making and take an interest in the problem and accept the organization's goals. And finally, forces in the situation, which include the type of leadership style, the organization values, the extent to which the group works efficiently as a unit, the problem and the resources needed to resolve it and the amount of time the leader takes to make the decision (Bateman \& Snell, 2004). These forces are critical areas in the healthcare industry and must be continuously examined and evaluated in different situations to determine the best choice of leadership style.

Since the emergence of this first model two other situational models have surfaced. The Vroom Model aids in the decision making and focuses on the participative dimension of leadership. The Path-Goal Theory deals with how leaders can influence their subordinates' perceptions of their work goals and the path they follow to achieve those goals (Bateman \& Snell, 2004). In the ever changing environment of the healthcare industry, administrators need to know what factors to consider when analyzing a situation and decide what leader decision style best fits the problem to be resolved. The Vroom Model of Leadership offers just that, factors in the areas of decision significance, knowing the significance of a decision and its impact to the success of the organization, the level of importance of team members to the decision, the leader's expertise, the commitment level of team members to the decision made by the leader, the group support for goals and their expertise and finally the capability of team members to work as a unit in resolving problems. These factors are then rated as High or Low in five style categories; decide, consult individually, consult group, facilitate and delegate (Bateman \& Snell, 2004). The style with the majority of High ratings will be the recommended style approach to that specific problem. This approach is particularly effective when administrators have to make major decisions, this process, even though complicated makes certain that the most important factors are considered; therefore, implementing the most appropriate style.

The Path-Goal Theory has two key situational factors; the characteristics of followers and environmental factors. These factors help to determine, which of the four behaviors will lead. The four leadership behaviors are; directive leadership, supportive leadership, participative and achievement-oriented leadership (Bateman \& Snell, 2004). Healthcare leaders in order to be successful, must communicate the goals of the organization, influence 
subordinates' perceptions of those goals and most importantly guide their subordinates in the right path in achieving those goals.

\section{The Final Analysis of Situational Leadership}

In is purest execution, situational leadership is about being able to move easily from a controlling leadership style to a serving leadership style based on the changing aspects of a situation. It takes adaptability to go from perspective needed to affirmatively and effectively address an organizational board to a perspective of serving the employees as if they were customers. In many organizations senior leaders act as if their only job is to change the boxes and the organizational chart and serve the needs and expectations of the board members and stockholders. The truth is that the employees are the internal customers of leadership and management. Developing a bonded and successful organizational democracy is not defined by the actions, values, or demands of leadership, rather through collaborative efforts. The goal of senior leadership should be clearing out the roadblocks and barriers that hinder employees from doing the appropriate and needed actions and activities (Bennis, 1992). This includes removing bureaucratic barriers that have been established even if they were originally established in the best interest of the organization.

Given the fact that situational leadership is based on the premise that leaders use a different style based on the situation and the maturity of the followers. Leaders also need to use a flexible platform to influence or respond to the traits and changing environment of organizational culture. This model would seem to have promise in the healthcare industry provided it includes monthly, quarterly, semi-annually goals, report cards, and measures.

\section{Theory and Observation}

How do we truly define the role of a leader in any organization, what are the characteristic of those individuals and its organizational culture? What has become very clear is that the culture the organizational infrastructure tends to dictate how it will service its customer both internal and external.

When observing the actions and thought processes that lead to decisions based on a particular situation, this is where the role of situational leadership or understanding of what it means to apply such actions becomes confusing to the organization and its customer. The healthcare industry itself can and is very difficult to manage on many levels, as mentioned previously it has become the numbers game more often. An example that comes to mind, is asking the question, why most hospitals are not funded adequately?

What is it about the management process that appears not to be able to handle its operational aspects of the job to the level in which its customers need to fully provide adequate healthcare. Again, we must try to understand what it fully means to apply the applications of situational management processes and theories into the day to day operation of the healthcare industry. Most of our leaders within the organization are limited in its ability to provide the best training for its employees, this also would relate to educational background and level of expertise.

This would constitute sometimes promoting not necessarily the best knowledgeable person, but the best available person. The questioned then comes to mind is the person a sectional thinker, or do they evaluate from a sit and wait approach. Maybe the person is a reactionary, based on the particulars of the obvious or not so obvious and how does that person understand what is needed to resolve the issue. When asked the question of short term as well as potential long-term needs, how do we attack the heart of that question? Another school of thought surrounding situational leadership, may suggest have more than one leader to share in the strategy approach, in to many instances leaders in the current workplace suggest sharing the load but not the knowledge to fully handle the load.

The ideal response would suggest having someone or group whom has an understanding of what the situation requires, it may in fact suggest something specifically related to that problem to be able to find a resolution. A leadership mentality approach is something that can be instilled in all workers; it can be a shared process which allows everyone involved to share in the maturation process of understanding the situational observational process and outcome. It is critical that we empower our employees to take a leadership approach towards solving problems and facing adversity in the workplace.

The workplace continues to evolve both in its culture and the relationship that it builds with its employees and its customers, the two eventually become one in the same, suggesting that we are all customers at some point. Having a full understanding of change will help with better managing employees who may have reservation about the process.

Four basic foundational concepts that should always serve as a part of any organizational structural development (1) Change management (2) Transitional leadership (3) Situational leadership (4) Cultural dynamics, the four areas mentioned play a vital role in the success of serving its customers both internal and external. On many occasions one or the other is almost underserved and it eventually leads to problems within the organization. The key is to somehow determine what is applicable and feasible to provide the best for both. 
This within itself will reduce some of the pitfalls in which most organization experience, situational leadership at the end of the day, simply suggest that the right people or groups of people can handle a situation knowing that they are at their best and their best are handling the task at hand most effectively.

\section{Distance learning executive programs that develop skills in situational leadership}

Several non-traditional university programs exist that provide a framework for developing situational leadership skills.

Colorado Technical University has an on-line Executive Doctor of Management program that requires 4 applied research projects instead of a dissertation. The program has classes and a curriculum focus on developing professionals with adaptive leadership skills.

http://www.instituteforadvancedstudies.com/

Colorado Technical University offers on-line graduate degrees in Management in Change Management and Conflict Management with focuses on the development of adaptive leadership skills

http:/www.ctuonline.edu/online-degree-programs/online-masters-degree-management/\#desc

http://www.ctuonline.edu/online-degree-programs/online-masters-degree-media-dispute-resolution-mba/

Mountain State University in West Virginia offers an on-line and weekend graduate degree in Strategic Leadership that can be completed in 12 months.

http://www.mountainstate.edu/majors/whystudy/sl/default.aspx

These courses can provide practical hands-on training for professionals on how to apply the practical applications of situational leadership in organizational problem solving. By developing these tools, while completing an advanced academic credential, leaders can enhance their ability to constructively adapt to organizational change.

\section{References}

Bateman, T. S., \& Snell, S. A. (2004). Management: The new competitive landscape, $6^{\text {th }}$ ed. McGraw-Hill/Irwin: New York, NY.

Bennis, W. (1992, April). The Art-form of Leadership. Training and Development.

Goleman, D., McKee, A. \& Boyatzis, R. (2002). Primal Leadership: Realizing the Power of Emotional Intelligence. Harvard Business School Press: Cambridge Mass.

Hatch, M. J. \& Cunliffe, A. L. (2006). Organizational Theory. Oxford Press: New York, NY.

Hencley, S.P. (1973). Situational behavioral approach to the study of educational leadership. In Cunningham, L. C. \& Gephart, W.J. (Eds.), Leadership: The Science and Art Today. (pp. 139-164).

Itaska, IL: F.E. Peacock Publishers.

Hernandez, D., Bumsted, S., Berger, L., \& Zwingman-Bagley, C. (1997, September). Nurse Leaders: roles driving organizational transition. Nursing Administration Quarterly, Vol. 22, 38(9).

Hersey, P. \& Blanchard, K. (1977). Management of organizational behavior: Utilizing Human Resources. Englewood Cliffs, NJ: Prentice-Hall.

Hoy, W.K. \& Miskel, C.G. (1987). Educational administration: Theory, research, and practice. Third Edition. New York: Random House.

Jobes, M. \& Steinbinder, A. (1996, January). Transitions in nursing leadership roles. Nursing Administration Quarterly. Vol. 20, 80. (5).

Kotter, J. P., (1990). What leaders really do. Harvard Business Review. 103-111. 
Krejci, J. W. \& Malin, S. (1997, September). Impact of leadership development on competencies. Nursing Economics. Vol. 15, 235(7).

Leebov, W. \& Scott, G.(1991). Health care managers in transition: Shifting roles and changing organizations. Boston: Jossey-Bass Inc., Publishers

McDonagh, K. J. (1998, January). The Nurse as Senior Health Care Executive. Nursing Administration Quarterly. Vol.22, 22(8).

Morrison, Ian. (1996). The second curve: Managing the velocity of change. New York: Ballantine Books.

Norris, W. R. \& Vecchio, R. P.(1992, September). Situational leadership theory: A replication. Group and Organization Management. Vol. 17(3), 331-12.

Schein, E. (1992). Organizational culture and leadership. Jossey Bass: San Francisco.

Sleeth, R. G. \& Johnston, W. R. (1996, Spring). The effective leader as a link between tasks and people. SAM Advanced Management Journal. Vol. 61(2), 16(6).

Sonnenfeld, J. A. (1985). Shedding light on the Hawthorne studies. Journal of Occupational Behavior, Vol. 6, 1985.

Tushman, M. L. \& O'Reilley, C. A. II.(1997). Winning through innovation: A Practical Guide to Leading Organizational Change and Renewal. Boston: Harvard Business School Press.

Vance, C. \& Larson, E. (2002, Summer). Leadership research in business and health care. Journal of Nursing Scholarship Vol. 34(2), 165 (7). 